ISSN: $2651-401 \mathrm{X}$

\title{
Mapping Urban Green Spaces Based on an Object-Oriented Approach
}

\section{Derya Gülçin ${ }^{1 *}$, Abdullah Akpınar ${ }^{1}$}

\begin{abstract}
The advent of technology and its implications on especially remote sensing image processing using High Resolution Satellite Images (HRSI) to map land cover provide researchers to monitor land changes, make landscape analyses, and manage land transformation. One of land dynamics that should be mapped for the sustainability of urban area is green spaces. Urban green spaces, such as parks, playgrounds, and residential greenery may promote both mental and physical health. Besides, they contribute to ecosystem services such as reducing heat island effect and carbon storage, aiding water regulation etc. Therefore, mapping urban green infrastructure from a high-resolution satellite image provides an important tool to conduct studies, researches, and projects for sustainable development of urban areas. As the material of this research, one of the orthophotos of Aydin urban area exemplifies the park, the green cover in the agricultural area, the playground, and the residential garden, was used. For classifying land cover from the orthophoto with Object-Based Image Analysis (OBIA), eCognition Developer 9.0 software was utilized. To combine spectral and shape features, multiresolution segmentation was implemented. Additionally, features as brightness and ratio green were used for the extraction of urban green areas. In this research, urban green areas were successfully extracted from the orthophoto and accuracy assessment was performed on the classified image. OBIA of high resolution imagery enables to extract detailed information of various targets on urban areas. The result of accuracy assessment of the classification achieved $84.68 \%$ overall accuracy. To increase the accuracy via manual interventions, manual classification tool of eCognition Developer 9.0 may be used if needed.
\end{abstract}

Keywords: Urban Green Space, Green İnfrastructure, Object-Based Classification, Aydin

\section{Introduction}

Urban areas are considered as economic, social, and cultural centers, which are also the most challenging areas for remote sensing analysis due to high spatial and spectral diversity of surface materials (Herold et al., 2003; Poursanidis et al., 2015; Hu et al., 2016). The spatial and spectral resolutions are significant in terms of the accuracy of classified image of an urban area generally incorporating built-up environment (artificial surfaces such as buildings, roads, sidewalks etc.), different vegetation covers (gardens, parks, urban forests, etc.), bare soil areas and water bodies. Mapping urban land cover provides the primary data for various studies such as change detection (Stefanov et al., 2011; Rogan and Chen, 2004; Shalaby and Tateishi, 2007; Rawat and Kumar, 2015), assessment of urban public health (Wolch et al., 2014; Akpinar, 2016), evaluation of urban ecosystem services (Derkzen et al., 2015; Baró et al., 2016; Grafius et al., 2016), and monitoring urban climate (Bechtel et al., 2015; Blok and Tschötschel, 2016). One of land dynamics that should be mapped for the sustainability of urban area is green spaces. Urban green spaces may promote both mental

1Department of Landscape Architecture, Agricultural Faculty, University of Adnan Menderes, 09010, Aydin, Turkey.

*Corresponding author: derya.yazgi@adu.edu.tr
Citation (Atıf): Gülçin D., Akpınar A., 2018. Mapping Urban Green Spaces Based on an Object-Oriented Approach. Bilge International Journal of Science and Technology Research, 2(special issue), 71-81. 
and physical health (Maas et al., 2006; Lee and Maheswaran, 2011; Akpinar, 2016). Besides, they contribute to ecosystem services such as reducing heat island effect and carbon storage, aiding water regulation etc. (Tzoulas et al., 2007; Derkzen et al., 2015). Therefore, mapping urban green infrastructure from a highresolution satellite image provides an important tool to conduct studies, researches, and projects for sustainable development of urban areas.

Based on remotely sensed data, image classification is an important process for mapping Land Use/Land Cover (LULC) (Foody, 2002; Bartholome and Belward, 2005). The development of image classification techniques has fostered the use of high resolution satellite images (HRSI) in remote sensing platforms with different approaches (Baltsavias, 1996; Lu and Wang, 2007; Blaschke, 2010; Schowengerdt, 2012; Khatami et al., 2016). High-resolution remote sensing technology provides strong support for the monitoring methods and evaluation indicators of urban environment. Although the increasing development of technology-based tools on especially remote sensing image processing, LULC mapping has a complicated procedure with a plenty of factors affecting the quality of the final product (Goodin et al., 2015). Therefore, selecting the accurate method to map LULC plays a key role for quantifying spatial information. As for the classification methods, pixel-based and object-based approaches have been widely used in remote sensing (Duro et al., 2012; Hussain et al., 2013; Xiong et al., 2017; Ierodiaconou et al., 2018). The advantages of object-based approach over the traditional pixel-based classification have been discussed in various researches and demonstrated its advantages over the pixel-based approach (Yan et al., 2006; Gao and Mas, 2008; Weih and Riggan, 2010; Myint et al., 2011; Huth et al., 2012). Object-based approach initially aggregates image pixels into spectrally homogenous image objects using an image segmentation algorithm and then classifies the individual objects while pixel-based classification focuses on individual pixels directly (Liu and Xia, 2010). In addition to this, object-based image classification groups pixels and considers their shapes and sizes with multi-resolution segmentation or segment mean shift (Gao and Mas, 2008; MacLean and Congalton, 2012). Multiresolution segmentation generates homogenous image objects by grouping pixels with different algorithms (Quian et al, 2007; Sahalu, 2014). Object-based approach combines three patterns (spectral, spatial, and temporal pattern) of feature information in general. Regarding spectral information, brightness values of the pixels are treated as features. Furthermore, spatial pattern analysis uses the neighborhood relationship of each pixel or cluster, size and shape of clusters. Moreover, temporal pattern analysis is helpful to make a change detection following a set of procedures for the classification (Jia, 2015).

According to the proposed various theories and methods for automatically acquiring information from HRSI, it is difficult to accurately extract all kinds of target information using only one method (Haala and Brenner, 1999; Benediktsson et al., 2003; You-Shui et al., 2004; Lu and Weng, 2009). As indicated in the relevant literature, the success of object-based classification is higher than pixel-based classification. Therefore, this research focuses on an object-based decision tree classification using an orthophoto of Aydin urban area and aims to present how can be urban green spaces mapped based on an object-oriented approach. In this context, it is comprehensively used the spectral features to extract the green space information from the test area that exemplifies the park, the green cover in the agricultural area, the playground, and the residential garden. For classifying land cover from the orthophoto with OBIA, eCognition Developer 9.0 software was utilized. To combine spectral and shape features, multiresolution segmentation was implemented. Additionally, features as brightness and Green-Red Vegetation Index (GRVI) were used for the extraction of urban green areas.

\section{Material and Method}

The research area is in Aydin Province, the southwestern part of Turkey. The dominant landscape type is fertile plain that irrigated by Great Meander. The province is bordered by the Aydin Mountains in the north and the Mentese Mountains in the south. The western end of the province is the Aegean coast with extensive salt marshes located around the river estuary and the Lake Bafa a major feature of the Menderes delta area (Yazgi and Yilmaz, 2017). The province has both rural and urban landscapes. According to the environmental report of Aydin, the average temperature is $17.7^{\circ} \mathrm{C}$, with an annual total rainfall of 645.1 $\mathrm{kg} / \mathrm{m} 2$ in 2016 (Anonymous, 2017). The weather is hot in summer and warm all year round influenced by Mediterranean climate. 
The research area is located on the fringe of Aydin urban settlement in the border of Mimar Sinan Neighborhood of Efeler district where the largest number of residential buildings has been built in the last decade. The satellite image captured in 2015 with $10 \mathrm{~cm}$ resolution and the development plan (DP) coded M19-b-12-d-4-c, which are the materials of this research, were derived from Aydin Metropolitan Municipality. The size of the image is $555 \times 700 \mathrm{~m}$ covering a total of $338.5 \mathrm{~m} 2$. Figure 1 highlights urban land uses and list of parks in the research area. We mainly focused on the park, the green cover in the agricultural area (olive grove), park with the playground, and the residential garden as urban green spaces. The orthophoto of the research area which has three spectral bands, Red, Green, Blue (RGB) is shown in Figure 2.

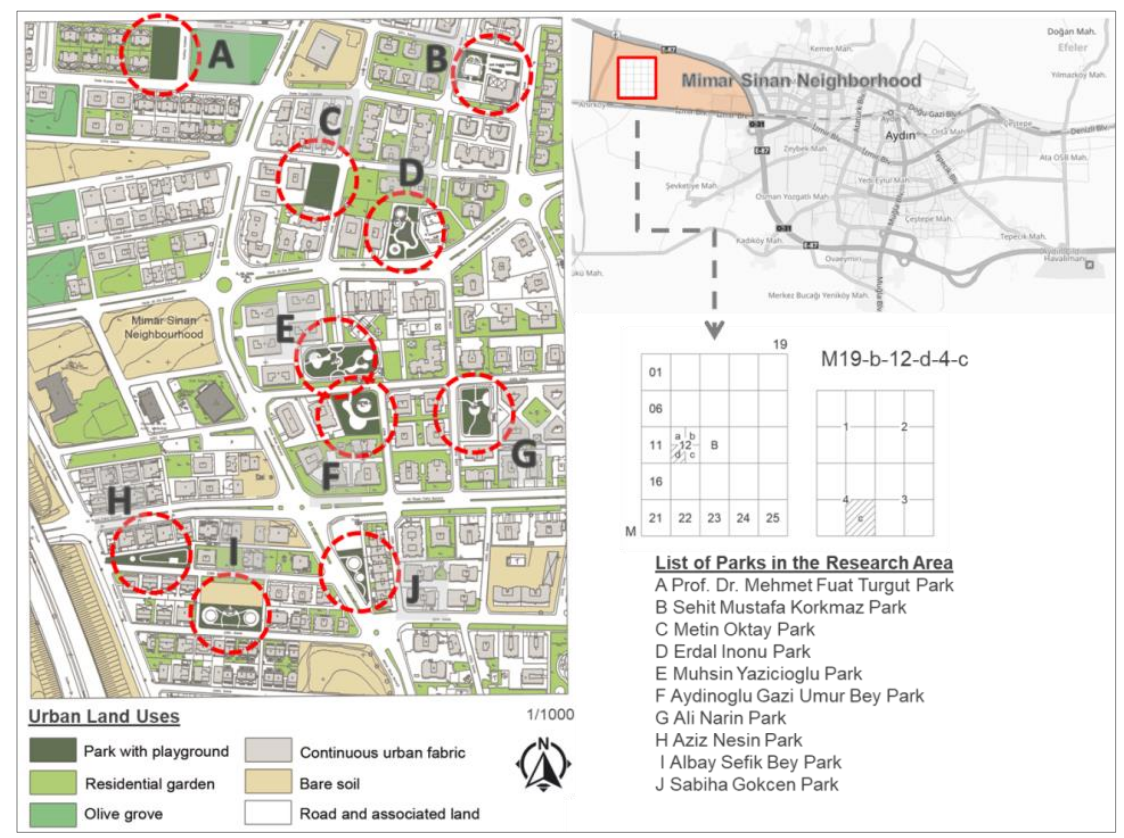

Figure 1. The location of the research area in Aydin urban settlement covering urban land uses and list of parks (Source: corresponding author)

OBIA of high resolution imagery enables to extract detailed information of various targets on urban areas. For classifying urban green spaces from the orthophoto with OBIA, eCognition Developer 9.0 software was utilized. As the primary step in the object-based approach, segmentation was processed with selecting optimal values for the main parameters (scale, shape, and compactness). Different combinations of these parameters were applied to find out suitable values. To combine spectral and shape features, multiresolution segmentation was implemented in this research which has been proven to be one of the most successful image segmentation algorithms in the OBIA framework (Neubert et al., 2008; Aguilar et al., 2016). Additionally, features as brightness and ratio green were used for the extraction of urban green areas.

As for calculating ratio green, Green-Red Vegetation Index (GRVI) formula was proposed as follows where pgreen was reflectance of visible green (Tucker, 1979; Motohka et al., 2010):

GRVI $=\left(\rho \_\right.$green $-\rho \_$red $) /\left(\rho \_\right.$green $+\rho \_$red $)$ 


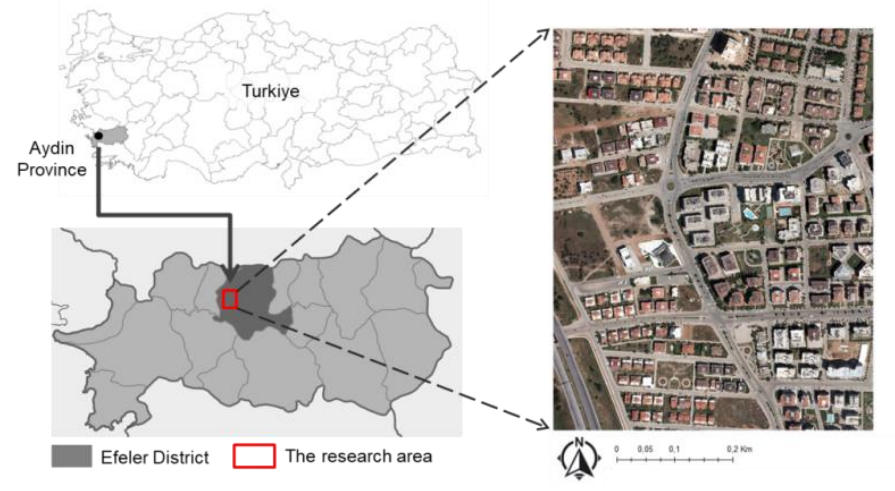

Figure 2. The location orthophoto of the research area in Aydin province

Brightness and ratio green values were estimated by applying a trial-and-error approach until finding the suitable value (Figure 3). In the last step, accuracy assessment was done and Kappa coefficient (Congalton, 1991) was computed as:

$$
\widehat{K}=\frac{N \cdot \sum_{i=1, n} x_{i i}-\sum_{i=1, n} x_{i+} \cdot x_{+i}}{N^{2}-\sum_{i=1, n} x_{i+} \cdot x_{+i}}
$$

(Where $\mathrm{n}, \mathrm{i}$ and $\mathrm{j}$ are the same as the former equation, $\mathrm{N}$ is the total number of observation, $x i+$ and $x+i$ are the number of total observations in the row $\mathrm{i}$ and the number of total observations in the column $\mathrm{i}$ respectively)
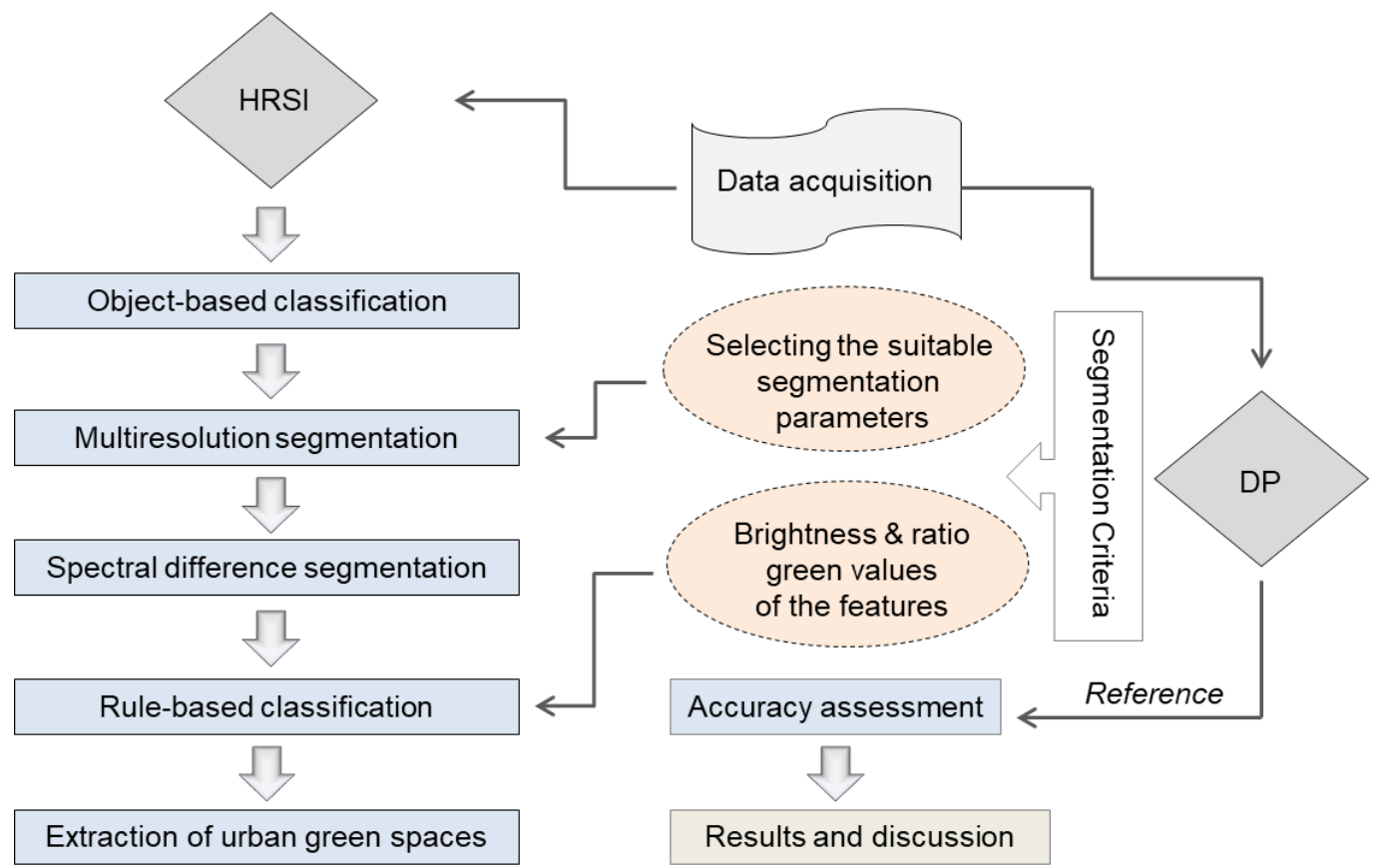

Figure 3. Proposed methodology 


\section{Results}

The orthophoto was loaded into eCognition Developer 9.0 and "Layer Mixing Tool" was used to set the equalizing to manual since there are only three layers in the image. To reduce the number of objects, a second level of segmentation was necessary. Therefore, segmentation phase consisted of two levels. First, regarded as a region-based algorithm, multiresolution segmentation was applied. Then, the segmentation parameters were defined after several trials (Figure 4). Layer weights were set to equal to one, scale equal to 30 , shape factor to 0.8 , and compactness to 0.5. Level 2 was for merging existing segments of level 1 based on the absolute spectral difference known as spectral difference segmentation (Yu et al., 2006; Kressler et al., 2005). This value changed between 5 and 15 and depends on the radiometric quality of the data. This allowed the merging of large homogenous objects, such as fields and parks, while keeping other objects separate such as buildings from the surrounding residential gardens (Kressler et al., 2005). The maximum spectral difference was set to 10 .

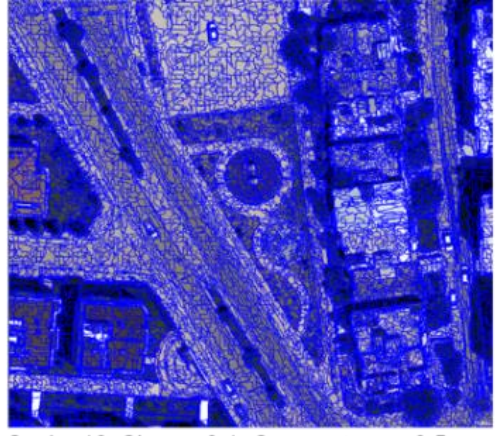

Scale: 10 , Shape: 0.1 , Compactness: 0.5

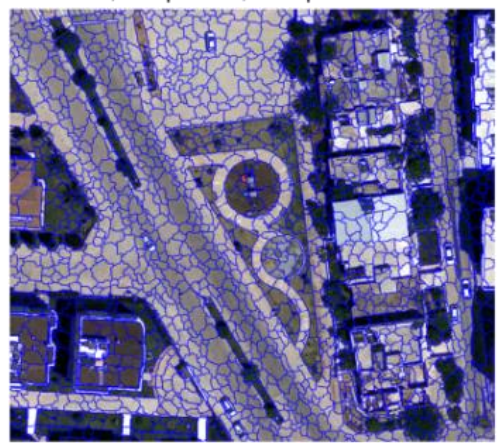

Scale: 20 , Shape: 0.8 , Compactness: 0.5

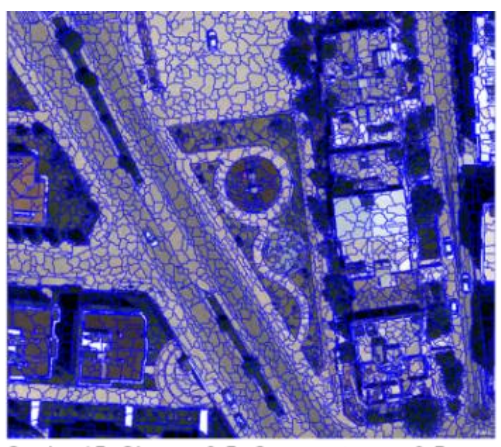

Scale: 15 , Shape: 0.5 , Compactness: 0.5

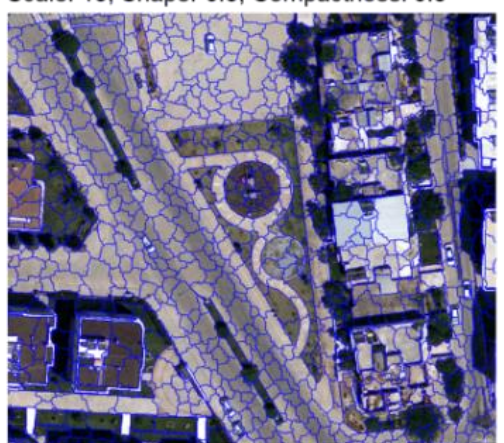

Scale: 30 , Shape: 0.8 , Compactness: 0.6

Figure 4. The segmentation results with different parameters

Brightness value appeared when double-clicked on the Brightness tag in the Feature View tree. The suitable values representing urban green spaces were between 57 and 84 (Figure 5). Following that, ratio green value was computed using layer arithmetic algorithm 

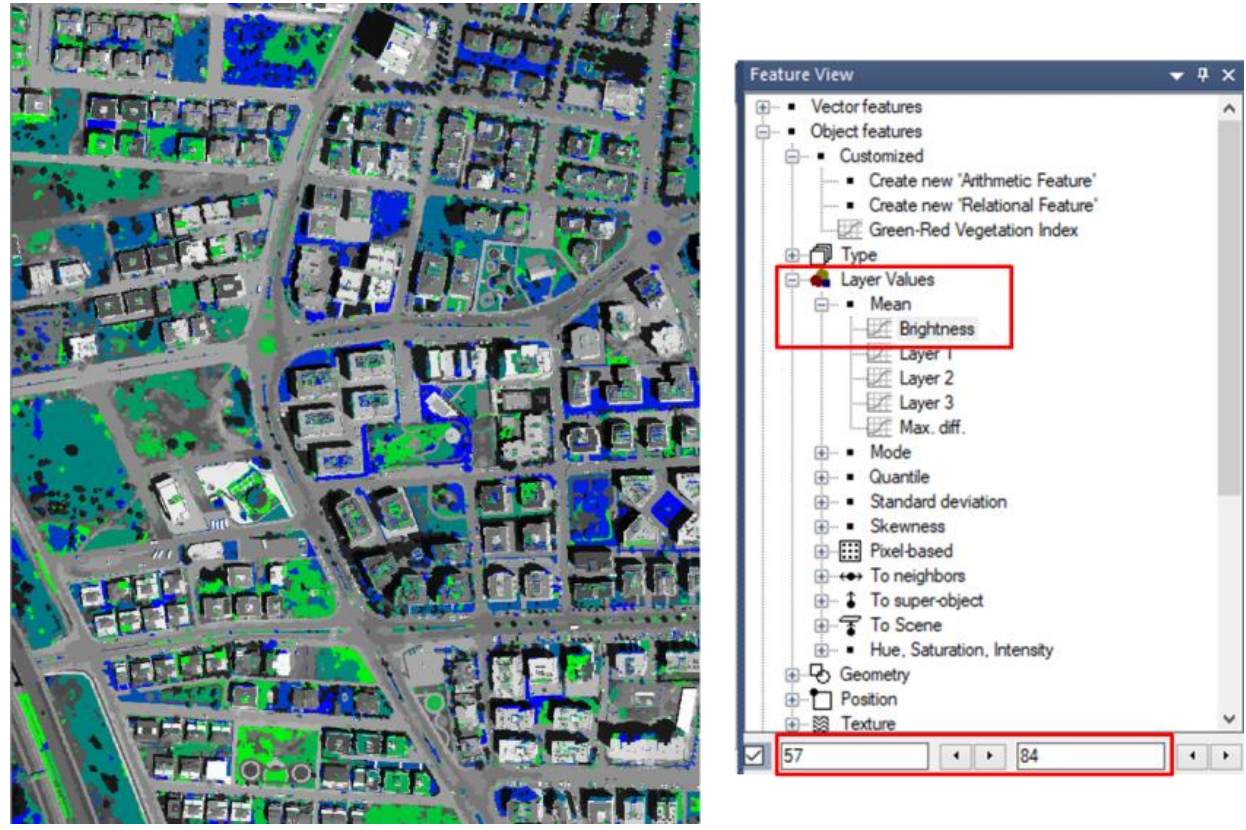

Figure 5. Brightness value range for classifying urban green space

The layer arithmetic algorithm provides to perform mathematical operations on layers of the image. The layers 1 through 3 are assigned as Red, Blue, and Green respectively (Figure 6). Ratio green value appeared when double-clicked on the GRVI tag in the Feature View tree under customized section. The suitable values representing urban green spaces changed between 131 and 173.
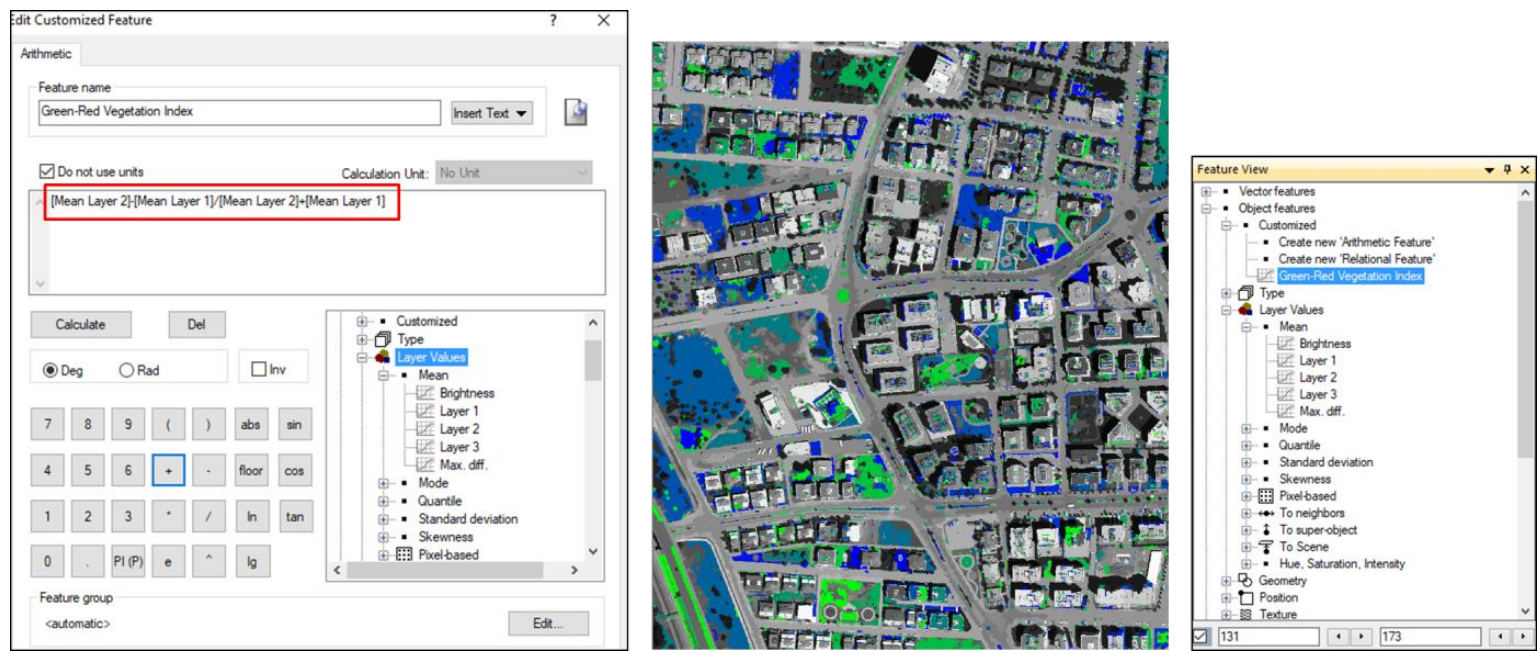

Figure 6. The calculation of ratio green using layer arithmetic algorithm

In the last step, "assign class" was processed according to the criteria that we defined. For using algorithm parameters, 'unclassified' box was overwritten in the Edit Process window. Then, conditions for brightness and ratio green values were assigned. When the classification was completed, some faulty classes were noticed on shadow and roof of the buildings due to their brightness and GRVI values. To prevent them, a second classification was done based on "area" and "brightness" values. For the brightness value, the range of 70-80 was recorded as a variable and for the area (pixel), 2500 was assigned after several trials (Figure 7). The fault classifications were determined as error and extracted from the classification. 


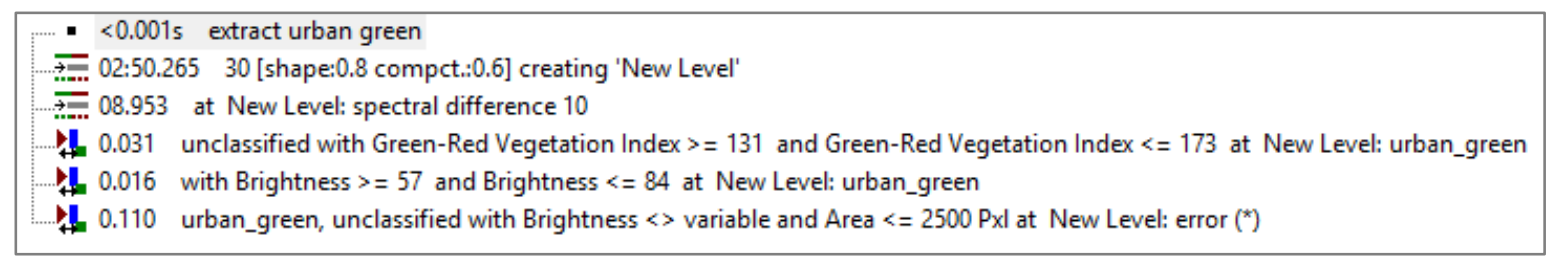

Figure 7. Classification steps in process tree of eCognition

\section{Discussion and Conclusions}

To evaluate the quality of the classification, accuracy assessment was performed. The overall accuracy was 84.68\% and Kappa coefficient was 0.84 which showed that the results were in the high level of agreement. The results provided from the orthophoto misclassified some parts of urban green spaces due to the spectral information of shadow. In addition to this, few parts of urban green spaces were not classified because of their brightness and GRVI values. There were also conflictions between bare soil and urban green spaces. It was understood that spontaneous vegetation cover on bare soil caused these conflictions. In similar cases, manual classification tool of eCognition can be used and the failures may be eliminated. Therefore, the overall accuracy of the final map can be improved. A second accuracy assessment was conducted to illustrate this as an example after manual classification (Figure 8).

Automatic mapping of land cover types in urban area is one of the most challenging issues in remote sensing (Hu et al., 2016; Jia et al., 2018). Despite the complexity of mapping LULC, various methods may be integrated with each other to produce accurate LULC maps. As it can be seen in previous studies, generating LULC databases with traditional methods are time consuming (Jia, 2015). In this paper, capacity of objectbased classification was tested to identify urban green spaces in a sample area of Aydin urban settlement. To conclude, this paper has elaborated a sample workflow that extracts urban green spaces from an orthophoto successfully which may be used as a reference for further remote sensing studies.

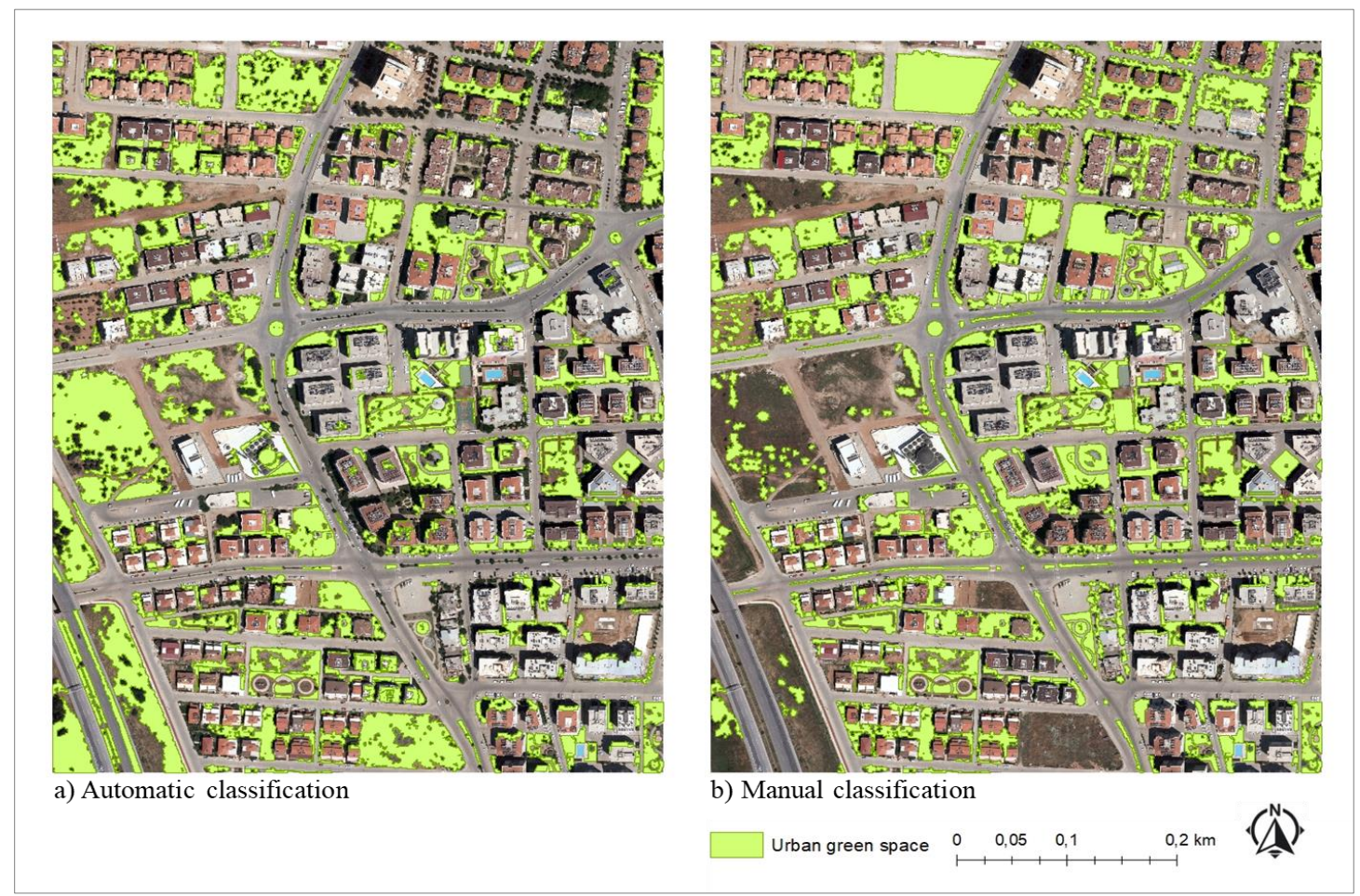

Figure 8. The extraction of urban green space with automatic and manual classification 


\section{Acknowledgements}

The satellite image captured in 2015 with $10 \mathrm{~cm}$ resolution and the development plan coded M19-b-12-d-4-c were provided from Municipality of Metropolitan City of Aydin. We would like to thank directorate of development and urban planning department and all data producers at the municipality.

\section{References}

Aguilar, M. A., Aguilar, F. J., Lorca, A. G., Guirado, E., Betlej, M., Cichón, P., Nemmaoui, A., Vallario, A., Parente, C. (2016). Assessment of Multiresolution Segmentation for Extracting Greenhouses from Worldview-2 imagery. International Archives of the Photogrammetry, Remote Sensing \& Spatial Information Sciences, 41.

Akpinar, A. (2016). How is quality of urban green spaces associated with physical activity and health?. Urban Forestry \& Urban Greening, 16: 76-83.

Anonymous (2017). Aydin Ili 2016 Yili Cevre Durum Raporu. Aydin Valiligi, Cevre ve Sehircilik Il Mudurlugu, 89s.

Baltsavias, E. P. (1996). Digital ortho-images - a powerful tool for the extraction of spatial-and geoinformation. ISPRS Journal of Photogrammetry and Remote sensing, 51(2): 63-77.

Baró, F., Palomo, I., Zulian, G., Vizcaino, P., Haase, D., Gómez-Baggethun, E. (2016). Mapping ecosystem service capacity, flow and demand for landscape and urban planning: A case study in the Barcelona metropolitan region. Land Use Policy, 57: 405-417.

Bartholome, E., Belward, A. S. (2005). GLC2000: A New Approach to Global Land Cover Mapping from Earth Observation Data. International Journal of Remote Sensing, 26(9): 1959-1977.

Bechtel, B., Alexander, P. J., Böhner, J., Ching, J., Conrad, O., Feddema, J., Mills, G., See, L., Stewart, I. (2015). Mapping local climate zones for a worldwide database of the form and function of cities. ISPRS International Journal of Geo-Information, 4(1): 199-219.

Benediktsson, J. A., Pesaresi, M., Amason, K. (2003). Classification and feature extraction for remote sensing images from urban areas based on morphological transformations. IEEE Transactions on Geoscience and Remote Sensing, 41(9): 1940-1949.

Blaschke, T. (2010). Object Based Image Analysis for Remote Sensing. ISPRS Journal of Photogrammetry and Remote Sensing, 65(1): 2-16.

Blok, A., Tschötschel, R. (2016). World port cities as cosmopolitan risk community: Mapping urban climate policy experiments in Europe and East Asia. Environment and Planning C: Government and Policy, 34(4): 717-736.

Congalton, R. G. (1991). A review of assessing the accuracy of classifications of remotely sensed data. Remote Sensing of Environment, 37(1): 35-46.

Derkzen, M. L., Teeffelen, A. J., Verburg, P. H. (2015). Quantifying urban ecosystem services based on high- resolution data of urban green space: an assessment for Rotterdam, the Netherlands. Journal of Applied Ecology, 52(4): 1020-1032.

Duro, D. C., Franklin, S. E., Dubé, M. G. (2012). A comparison of pixel-based and object-based image analysis with selected machine learning algorithms for the classification of agricultural landscapes using SPOT-5 HRG imagery. Remote Sensing of Environment, 118: 259-272.

Foody, G. M. (2002). Status of Land Cover Classification Accuracy Assessment. Remote Sensing of Environment, 80(1): 185-201.

Gao, Y and Mas, J. F. (2008). A Comparison of the Performance of Pixel Based and Object Based Classifications over Images with Various Spatial Resolutions. Online Journal of Earth Sciences, 2(1): $27-35$. 
Goodin, D. G., Anibas, K. L., Bezymennyi, M. (2015). Mapping land cover and land use from object-based classification: an example from a complex agricultural landscape. International Journal of Remote Sensing, 36(18): 4702-4723.

Grafius, D. R., Corstanje, R., Warren, P. H., Evans, K. L., Hancock, S., Harris, J. A. (2016). The impact of land use/land cover scale on modelling urban ecosystem services. Landscape Ecology, 31(7): 15091522 .

Haala, N., Brenner, C. (1999). Extraction of buildings and trees in urban environments. ISPRS Journal of Photogrammetry and Remote Sensing, 54(2-3): 130-137.

Herold, M., Scepan, J., Müller, A., Günther, S. (2002). Object-oriented mapping and analysis of urban land use/cover using IKONOS data. In 22nd Earsel Symposium Geoinformation for European-Wide Integration (pp. 4-6).

Hu, T., Yang, J., Li, X., Gong, P. (2016). Mapping urban land use by using landsat images and open social data. Remote Sensing, 8(2): 151.

Hussain, M., Chen, D., Cheng, A., Wei, H., Stanley, D. (2013). Change detection from remotely sensed images: From pixel-based to object-based approaches. ISPRS Journal of Photogrammetry and Remote Sensing, 80: 91-106.

Huth, J., Kuenzer, C., Wehrmann, T., Gebhardt, S., Tuan, V. Q., Dech, S. (2012). Land cover and land use classification with TWOPAC: Towards automated processing for pixel-and object-based image classification. Remote Sensing, 4(9): 2530-2553.

Ierodiaconou, D., Schimel, A. C., Kennedy, D., Monk, J., Gaylard, G., Young, M., Diesing, M., Rattray, A. (2018). Combining pixel and object based image analysis of ultra-high resolution multibeam bathymetry and backscatter for habitat mapping in shallow marine waters. Marine Geophysical Research, 39(1-2), 271-288.

Jia, Y. (2015). Object-based Land Cover Classification with Orthophoto and LIDAR Data. Master of Science Thesis, Royal Institute of Technology (KTH) Stockholm, Sweden.

Jia, Y., Ge, Y., Ling, F., Guo, X., Wang, J., Wang, L., Chen, Y., Li, X. (2018). Urban Land Use Mapping by Combining Remote Sensing Imagery and Mobile Phone Positioning Data. Remote Sensing, 10(3), 446.

Khatami, R., Mountrakis, G., Stehman, S. V. (2016). A meta-analysis of remote sensing research on supervised pixel-based land-cover image classification processes: General guidelines for practitioners and future research. Remote Sensing of Environment, 177: 89-100.

Kressler, F. P., Steinnocher, K., Franzen, M. (2005). Object-oriented classification of orthophotos to support update of spatial databases. In Geoscience and Remote Sensing Symposium, 2005. IGARSS'05. Proceedings. 2005 IEEE International (Vol. 1, pp. 4-pp). IEEE.

Lee, A. C., Maheswaran, R. (2011). The health benefits of urban green spaces: a review of the evidence. Journal of Public Health, 33(2): 212-222.

Liu, D., Xia, F. (2010). Assessing object-based classification: advantages and limitations. Remote Sensing Letters, 1(4): 187-194.

Lu, D., Weng, Q. (2009). Extraction of urban impervious surfaces from an IKONOS image. International Journal of Remote Sensing, 30(5): 1297-1311.

Maas, J., Verheij, R. A., Groenewegen, P. P., De Vries, S., Spreeuwenberg, P. (2006). Green space, urbanity, and health: how strong is the relation?. Journal of Epidemiology \& Community Health, 60(7): 587592.

MacLean, M. G and Congalton, R. G. (2012). Map accuracy assessment issues when using an object-oriented approach. In Proceedings of the American Society for Photogrammetry and Remote Sensing 2012 Annual Conference. 
Motohka, T., Nasahara, K. N., Oguma, H., \& Tsuchida, S. (2010). Applicability of green-red vegetation index for remote sensing of vegetation phenology. Remote Sensing, 2(10): 2369-2387.

Myint, S. W., Gober, P., Brazel, A., Grossman-Clarke, S., Weng, Q. (2011). Per-pixel vs. object-based classification of urban land cover extraction using high spatial resolution imagery. Remote sensing of environment, 115(5): 1145-1161.

Neubert, M., Herold, H., Meinel, G. (2008). Assessing image segmentation quality-concepts, methods and application. In Object-based image analysis (pp. 769-784). Springer, Berlin, Heidelberg.

Poursanidis, D., Chrysoulakis, N., Mitraka, Z. (2015). Landsat 8 vs. Landsat 5: A comparison based on urban and peri-urban land cover mapping. International Journal of Applied Earth Observation and Geoinformation, 35: 259-269.

Qian, J., Zhou, Q and Hou, Q. (2007). Comparison of pixel-based and object-oriented classification methods for extracting built-up areas in aridzone. In ISPRS Workshop on Updating Geo-Spatial Databases with Imagery \& The 5th ISPRS Workshop on DMGISs (pp. 163-171).

Rawat, J. S., Kumar, M. (2015). Monitoring land use/cover change using remote sensing and GIS techniques: A case study of Hawalbagh block, district Almora, Uttarakhand, India. The Egyptian Journal of Remote Sensing and Space Science, 18(1): 77-84.

Rogan, J., Chen, D. (2004). Remote sensing technology for mapping and monitoring land-cover and land-use change. Progress in Planning, 61(4): 301-325.

Sahalu, A. G. (2014). Analysis of urban land use and land cover changes: a case of study in Bahir Dar, Ethiopia (Doctoral dissertation).

Schowengerdt, R. A. (2012). Techniques for Image Processing and Classifications in Remote Sensing. Academic Press. ISBN 0126289808, 9780126289800, 249 p.

Shalaby, A., Tateishi, R. (2007). Remote sensing and GIS for mapping and monitoring land cover and landuse changes in the Northwestern coastal zone of Egypt. Applied Geography, 27(1): 28-41.

Stefanov, W. L., Ramsey, M. S., Christensen, P. R. (2001). Monitoring urban land cover change: An expert system approach to land cover classification of semiarid to arid urban centers. Remote Sensing of Environment, 77(2): 173-185.

Tucker, C. J. (1979). Red and photographic infrared linear combinations for monitoring vegetation. Remote Sensing of Environment, 8(2): 127-150.

Tzoulas, K., Korpela, K., Venn, S., Yli-Pelkonen, V., Kaźmierczak, A., Niemela, J., James, P. (2007). Promoting ecosystem and human health in urban areas using Green Infrastructure: A literature review. Landscape and urban planning, 81(3): 167-178.

Weih, R. C., Riggan, N. D. (2010). Object-based classification vs. pixel-based classification: Comparative importance of multi-resolution imagery. The International Archives of the Photogrammetry, Remote Sensing and Spatial Information Sciences, 38(4), C7.

Xiong, J., Thenkabail, P. S., Tilton, J. C., Gumma, M. K., Teluguntla, P., Oliphant, A., Congalton, R. G., Yadav, K., Gorelick, N. (2017). Nominal 30-m cropland extent map of continental Africa by integrating pixel-based and object-based algorithms using sentinel-2 and Landsat-8 data on Google earth engine. Remote Sensing, 9(10): 1065.

Yan, G., Mas, J. F., Maathuis, B. H. P., Xiangmin, Z., Van Dijk, P. M. (2006). Comparison of pixel- based and object- oriented image classification approaches - a case study in a coal fire area, Wuda, Inner Mongolia, China. International Journal of Remote Sensing, 27(18): 4039-4055.

Yazgi, D., Yilmaz, K. T. (2017). The Assessment of Landscape Fragmentation in an Agricultural Environment Degradation or Contribution to Ecosystem Services? Fresenius Environmental Bulletin, 26(12A): 7941-7950. 
You-Shui, Z., Xue-Zhi, F., Jin-Kang, D., \& Guo-Qin, G. (2004). Study on extraction of urban green space from IKONOS remote sensing images. 地理研究, 23(2): 274-280.

Yu, Q., Gong, P., Clinton, N., Biging, G., Kelly, M., Schirokauer, D. (2006). Object-based detailed vegetation classification with airborne high spatial resolution remote sensing imagery. Photogrammetric Engineering \& Remote Sensing, 72(7): 799-811. 